\title{
Differential response of Qilian juniper radial growth to climate variations in the middle of Qilian Mountains and the northeastern Qaidam Basin
}

\author{
Wenzhi Wang ${ }^{1,2} \cdot$ Xiaohong Liu ${ }^{1} \cdot$ Xuemei Shao ${ }^{3}$ • \\ Dahe Qin ${ }^{1} \cdot$ Guobao Xu ${ }^{1,2} \cdot$ Bo Wang ${ }^{1,2}$. \\ Xiaomin Zeng ${ }^{1,2} \cdot$ Guoju Wu ${ }^{1,2} \cdot$ Xuanwen Zhang ${ }^{1,2}$
}

Received: 4 October 2014 / Accepted: 8 July 2015 /Published online: 21 July 2015

(C) Springer Science+Business Media Dordrecht 2015

\begin{abstract}
Tree growth in the mid-latitudes of the northern hemisphere reveals significant interannual variation in carbon sequestration, and the variations have been widely attributed to climate change, especially to the recent rapid warming and increasing drought stress. However, the response of natural trees under the different regions that exist in the northeastern QinghaiTibetan Plateau remains unclear. Here, we use nine Qilian juniper (Sabina przewalskii) treering width and basal area increment (BAI) chronologies from the middle of the Qilian Mountains and the northeastern Qaidam Basin to quantify tree growth trends and their response to the recent rapid warming. The trees, growing at high and low elevations, exhibited a consistent pattern of inter-annual variations, with increasing synchronicity in their trends since 1950. Responses to several climate factors indicate that increasing temperature accelerated tree growth in the middle of the Qilian Mountains, but restricted tree growth in the northeastern Qaidam Basin. Moving-window correlation analyses demonstrate a clearly contrasting response to the temperature variations. Our findings suggest that growth of Qilian juniper in the middle of the Qilian Mountains will increase steadily in the future rapid warming, but may remain constant or even decrease in the northeastern Qaidam Basin. These contrasting responses to temperatures provide valuable information on forest dynamics
\end{abstract}

Electronic supplementary material The online version of this article (doi:10.1007/s10584-015-1467-2) contains supplementary material, which is available to authorized users.

Xiaohong Liu

liuxh@1zb.ac.cn

1 State Key Laboratory of Cryospheric Sciences Cold and Arid Regions Environmental and Engineering Research Institute, Chinese Academy of Sciences, No. 320 Donggang West Road, Lanzhou 730000, China

2 University of Chinese Academy of Sciences, Beijing 100049, China

3 Institute of Geographical Sciences and Natural Resources Research, Chinese Academy of Sciences, Beijing 100101, China 
in the critical mid-latitude regions that should be incorporated into predictions of future forest carbon cycling under global warming.

\section{Introduction}

Trees absorb large quantities of carbon from atmospheric $\mathrm{CO}_{2}$ and store this carbon for long periods, but they also release carbon through leaf abscission, loss of twigs and branches, and decomposition of fallen parts; these processes form a critical component of the terrestrial carbon cycle (Anderegg et al. 2013; Williams et al. 2013; Fang et al. 2014). In response to the dramatic environmental changes that have been occurring in recent decades, especially increasing $\mathrm{CO}_{2}$ levels and the associated global warming, many studies have been conducted on tree growth and carbon (C) sequestration in many parts of the world, using a range of approaches (Liu et al. 2013; Fang et al. 2014; Wu et al. 2014a; Yu et al. 2014). Forest inventories and eddy covariance observations have revealed enhanced tree growth in Japan and in subtropical forests governed by the East Asian monsoon (Fang et al. 2014; Yu et al. 2014). Model simulations have suggested that climate change has mainly increased growth in maritime and boreal regions of British Columbia (B.C.), Canada's forests (Wu et al. 2014a). However, dendrochronological methods have found that tree growth has declined substantially around the world, and mortality has increased in some cases, during recent decades (Allen et al. 2010; Williams et al. 2010; Peñuelas et al. 2011; Liu et al. 2013). Increasing temperatures and drought stress appear to be the primary factors that control the response of tree growth (Anderegg et al. 2013; Williams et al. 2013). Therefore, climate change has been recognized as playing a vital role in forest ecosystems.

Warming trends have been particularly pronounced in semi-arid regions, especially in the northern mid-latitude regions, during the last century (Huang et al. 2012). Furthermore, semiarid and arid forests are of particular importance for global carbon cycles because the large interannual variability in the global carbon sink appears to have been driven by changes in the growth of vegetation in semi-arid areas (Poulter et al. 2014). Ongoing changes due to rapid warming of semi-arid and arid regions are altering tree growth conditions for many species worldwide (Allen et al. 2010). Evidence from tree-ring width series suggests that tree growth declines in central Asia have been confined to forests in semi-arid regions (Liu et al. 2013). Forests within the semi-arid southwestern United States have also experienced substantially reduced growth in recent decades, and are predicted to continue this trend in the 21st century (Williams et al. 2010). However, little attention has been paid to tree growth in the different regions of northeastern Qinghai-Tibetan Plateau, where the warming trend has been stronger than in most other regions (Chen et al. 2013).

Here, we sampled and developed seven new tree ring chronologies from living Qilian juniper located in the middle of the Qilian Mountains and the northeastern Qaidam Basin to evaluate the growth trends in recent decades. In the middle of the Qilian Mountains, we sampled three sites at a high elevation (near the upper treeline) and three sites at a lower elevation to detect and explore any differences in their growth trends. We also combined two previous chronologies in the northeastern Qaidam Basin. To address how climate change has influenced tree growth, we used dendrochronological methods to understand the reactions of Qilian juniper to climatic variations in these regions of the northeastern Qinghai-Tibetan Plateau. We also used moving-window correlation analysis to quantify the effects of interannual to multi-decadal climatic variation on radial growth of Qilian juniper. 


\section{Materials and methods}

\subsection{Study area}

We selected the middle of Qilian Mountains and the northeastern Qaidam Basin as our study areas. The two study areas are both located in the northeastern Qinghai-Tibetan Plateau, and they are about $300 \mathrm{~km}$ apart (Fig. 1a). The two region's climates are both under a strong continental influence, and are characterized by long, cold, and dry winters. In the middle of the Qilian Mountains and the northeastern Qaidam Basin, total annual precipitation averaged 309 and $153 \mathrm{~mm}$, respectively, during the common period for which data is available (from 1960 to 2008, Fig. 1b). The mean annual temperature was $0.70{ }^{\circ} \mathrm{C}$ in the middle of the Qilian Mountains, with monthly means ranging from $-14.37{ }^{\circ} \mathrm{C}$ in January to $13.44{ }^{\circ} \mathrm{C}$ in July, and $2.95^{\circ} \mathrm{C}$ in the northeastern Qaidam Basin, with monthly means ranging from $-11.48^{\circ} \mathrm{C}$ in January to $15.45^{\circ} \mathrm{C}$ in July (Fig. 1b). The dominant tree species in the study areas are Qilian juniper and Qinghai spruce (Picea crassifolia). Qilian juniper is mostly distributed on sunny slopes at elevations of 3000 to $3600 \mathrm{~m}$ a.s.l. in the middle of the Qilian Mountains and 3500 to $4000 \mathrm{~m}$ a.s.l. in the northeastern Qaidam Basin. The species can survive intense drought, and therefore represents an important drought-tolerant species of the forest-steppe ecotone. The soils are generally similar in the two regions (primarily loess deposits), with a thickness of 20 to $50 \mathrm{~cm}$ on gentle slopes, but they are thinner and may even disappear entirely on steep, eroded slopes in the mountains.

\subsection{Field sampling and dendrochronological methods}

In the middle of the Qilian Mountains, we tried to obtain two core samples per living tree from Qilian junipers at three high-elevation and three low-elevation sites in May of 2013. The range of elevations was 200 to $300 \mathrm{~m}$ at each site. In the northeastern Qaidam Basin, we sampled from Qilian junipers at the Delingha County, where China's longest tree ring width chronology was developed (Shao et al. 2010; Yang et al. 2014).

After air-drying and sanding the cores in the laboratory, we measured the ring widths to a precision of $0.01 \mathrm{~mm}$ and confirmed their dates using the COFECHA software (Holmes 1983). In addition, we used two published tree-ring chronologies from the Delingha County of the northeastern Qaidam Basin to improve our geographical coverage of Qilian juniper growth (Shao et al. 2009). In total, nine Qilian juniper tree-ring chronologies were used in the present study. We used negativeexponential or linear regression models to detrend the age series for each tree and developed the tree-ring width chronology using the ARSTAN software (Cook 1985). Table S1 provides detailed information about the sampling sites and their tree-ring dating characteristics. In the present analysis, we focused primarily on the tree growth trends and their response to recent climate change. Based on the overlapping periods in our data, we obtained the tree-ring width and raw ring width series since 1800, with the longest periods extending from 1800 to 2012 in the middle of the Qilian Mountain and from 1800 to 2008 for the northeastern Qaidam Basin.

Ring width in mature trees declines with age. Thus, if a change in growth trends is suspected, it may be impossible to investigate the trend based solely on the changes in ring width. Actually, the conversion of radial increment (ring width) into basal area increment (BAI) can overcome this problem (Phipps and Whiton 1988). Present, we derived an annual 


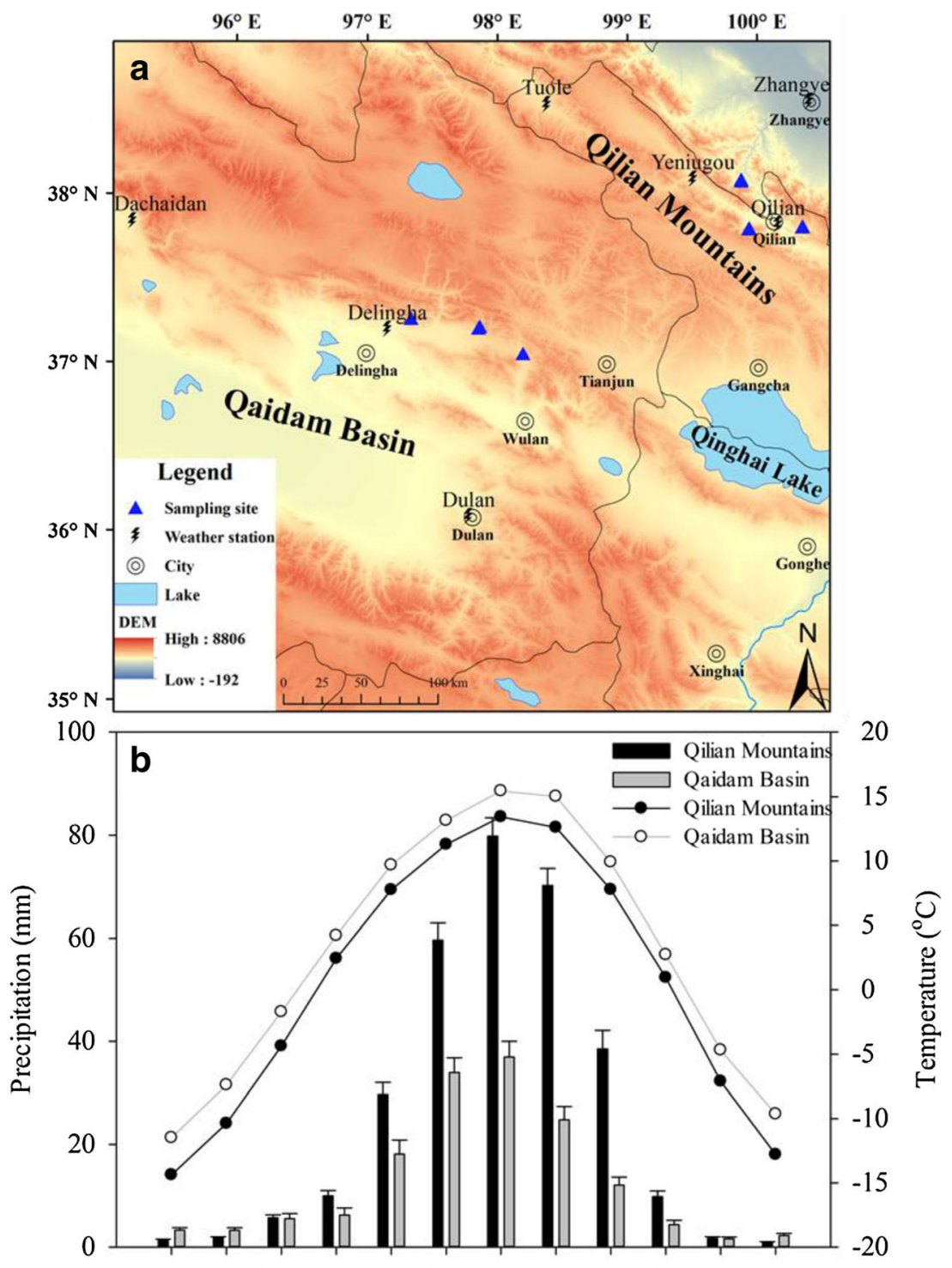

Jan. Feb. Mar. Apr. May June July Aug. Sept. Oct. Nov. Dec.

\section{Month}

Fig. 1 a Locations of the study areas and of the sampling sites in the middle of the Qilian Mountains and in the northeastern Qaidam Basin. b Mean monthly temperature (lines) and mean monthly precipitation (bars, $\pm 1 \mathrm{SE}$ ) for the common period from 1960 to 2008 for the two regions

BAI series at each site, calculated forward from the pith to the bark, from the averaged raw ring widths based on the assumption of concentrically distributed tree rings (Phipps and Whiton 1988):

$$
\mathrm{BAI}=\pi \times\left(R_{n}^{2}-R_{n-1}^{2}\right)
$$


where $R$ is the radius of the averaged ring width from all trees that had distinct growth rings in a given year and $n$ is the year of tree-ring formation. However, Qilian juniper trees are typically of strip-bark forms, then, the assumption of concentrically distributed principle, in some way, may be not conformed. Nevertheless, the BAI method provides an additional evidence to detect the long-term tree growth trends.

A recent study reviewed and evaluated the four different widely used methods to detect long-term tree growth trends and suggested applying multiple methods when analyzing trends (Peters et al. 2015). Here, we used both the tree-ring width series deduced from the conservative detrending method and the BAI chronologies to detect the recent Qilian juniper growth trends. We also compared the conservative detrending series and the previous published reconstructed precipitation variations using signal-free regional curve standardization method (Fig. S1, Yang et al. 2014) in the northeastern Qaidam Basin, and found they are correlated significantly $(r=0.92, p<0.001)$ with each other during the period 1800 to 2008 .

\subsection{Data analysis}

We obtained climate data from four meteorological stations (Qilian, Yeniugou, Tuole, and Zhangye) in the middle of the Qilian Mountains. For the northeastern Qaidam Basin, climate values from the Dulan, Delingha, and Dachaidan meteorological stations (Table S2). The climate variables were the monthly maximum temperature $\left(T_{\max }\right)$, monthly mean temperature $\left(T_{\text {mean }}\right)$, monthly minimum temperature $\left(T_{\min }\right)$ and monthly total precipitation. All the meteorological datasets were obtained from the National Climate Center, China Meteorological Administration. Due to the different altitudes of the weather stations, the monthly mean precipitation and temperature were first scaled and then used long-term mean values to calculate separately for each month of the year in the two regions respectively (Yang et al. 2014). The time spans for the middle of the Qilian Mountains and the northeastern Qaidam Basin climate data were from 1960 to 2012 and from 1957 to 2008 , respectively. To detect the regional climate and tree growth trends, the Mann-Kendall trend tests were used. We tested their significance using the Theil-Sen trend estimate (http://www.singlecaseresearch.org/calculators/theil-sen). Due to differences in the absolute values of the different BAI chronologies, we first normalized each series to produce standard $Z$-scores, and then averaged the results to produce composite BAI chronologies for the two regions. To avoid the low-frequency trends of the climate parameters and the tree growth series, we calculated the high-frequency signal (i.e., the residuals from the linear trend fit) derived from the BAI, tree-ring width series and the four climate parameters (the monthly $T_{\text {mean }}, T_{\min }$, $T_{\max }$, and total precipitation). We correlated the high-frequency residuals with the interannual climatic variations from the previous August to the current October for both regions. We also used either a 21-year or a 30-year moving-window correlation analysis to calculate the temporal stability of the time series. Correlation and Z-score analyses were conducted using the SPSS 16.0 statistical package (SPSS, Chicago, IL, USA).

\section{Results}

\subsection{Climatic trends}

During the common period from 1960 to 2008, there has been a continuous and significant warming trend (Table 1, Fig. S2). In the middle of the Qilian Mountains, annual $T_{\text {mean }}$ 


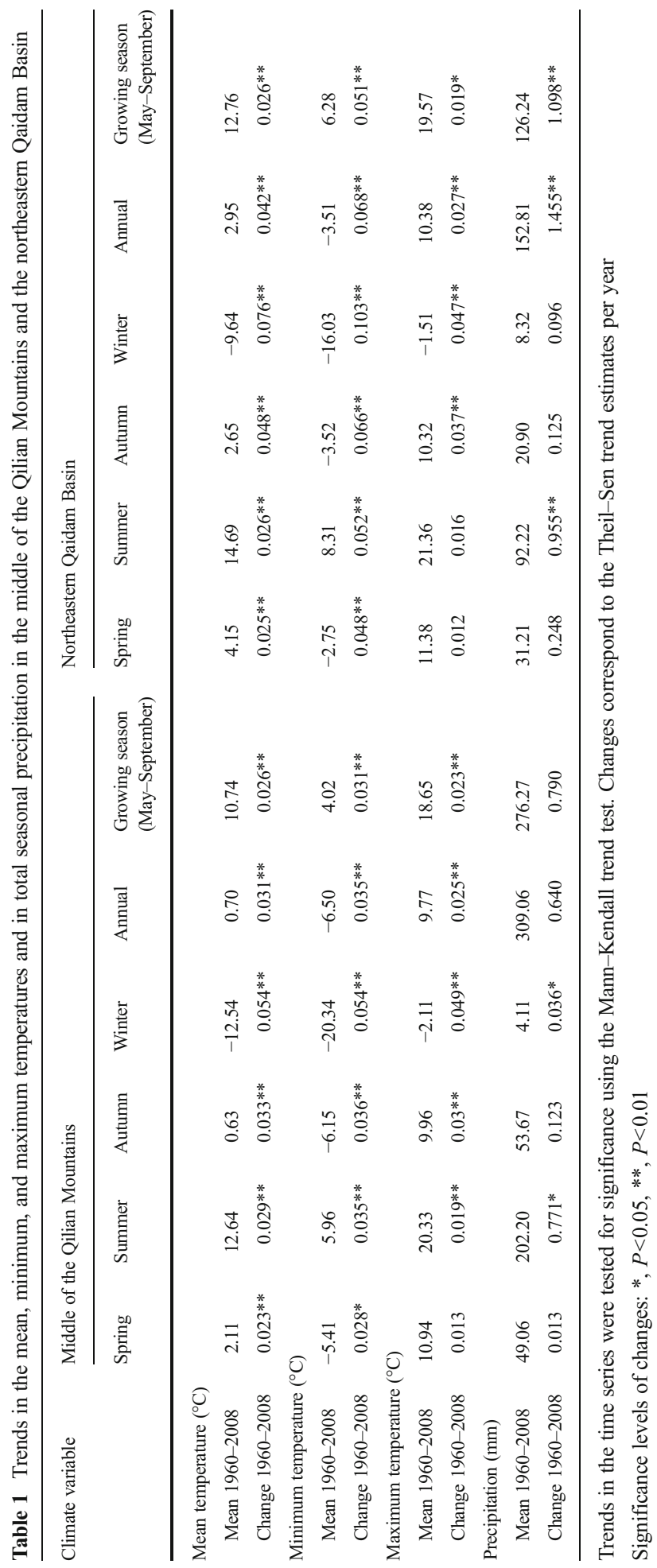


increased significantly, at a rate of $0.31{ }^{\circ} \mathrm{C}$ per decade. The $T_{\text {mean }}$ in spring, summer, autumn, and winter also increased significantly, at rates of $0.23,0.29,0.33$, and $0.54{ }^{\circ} \mathrm{C}$ per decade, respectively. Winter warming was about twice as fast at the spring and summer warming. The mean growing season temperature (May-September) increased at a rate of $0.26{ }^{\circ} \mathrm{C}$ per decade from 1960 to 2008 (Table 1). Moreover, the monthly $T_{\min }$ and $T_{\max }$ also increased significantly, and $T_{\min }$ increased faster than $T_{\max }$ in all periods, thereby decreasing the diurnal temperature range. Although the annual precipitation increased at a rate of $6.4 \mathrm{~mm}$ per decade, the increase was not statistically significant $(p>0.05)$; however, precipitation increased significantly in summer and winter, though the rate of increase was an order of magnitude greater during the summer. Fig. S2 shows that growing season precipitation ranged from $204.7 \mathrm{~mm}$ (1991) to $385.4 \mathrm{~mm}$ (1998).

In the northeastern Qaidam Basin, significant increases occurred in all three temperature parameters $\left(T_{\max }, T_{\text {mean }}\right.$, and $\left.T_{\min }\right)$ and in precipitation (Table 1). The mean growing season temperature increased at a rate of $0.26{ }^{\circ} \mathrm{C}$ per decade, which is equal to that in the middle of the Qilian Mountains, but the growing season precipitation increased faster in this arid basin (at $10.98 \mathrm{~mm}$ per decade, $p<0.01$ ). Growing season precipitation ranged from $53.6 \mathrm{~mm}$ (1961) to $226.7 \mathrm{~mm}$ (2002) in this region (Fig. S2). The coefficient of variation for precipitation was larger in the northeastern Qaidam Basin than in the middle of the Qilian Mountains (30.1 and $13.6 \%$, respectively).

\subsection{Tree growth trends}

In the middle of the Qilian Mountains, mean raw ring width and BAI were smaller at the highelevation sites than at the low-elevation sites during the period from 1800 to 2012 (Table 2); nevertheless, the means for the high-elevation sites were generally equivalent to or higher than those of the low-elevation sites during the period from 1950 to 2012. Trend analysis revealed that raw ring width, BAI and tree-ring width series increased significantly at the high-elevation sites, for the low-elevation sites, raw ring width, BAI and tree-ring width series increased significantly at SDL-L (Table 2). Mean $Z$-scores for the high- and low-elevation BAI and tree-ring width chronologies both revealed substantial common periods of enhanced tree growth from 1950 to 2012 (Fig. 2a, c), the growth increased faster in the high-elevation chronology than in the low-elevation series. However, an independentsamples $t$ test found no significant difference between the first-order differences in the two time-series $(n=63, p>0.05)$. The correlations between the two chronologies were temporally stable based on the 30-year moving-window correlation analysis (Fig. 2a, c, bottom). These results indicated that growth of Qilian juniper at both elevations exhibited a consistent pattern of inter-annual variation. We therefore averaged the high- and low-elevations tree growth chronologies to represent the overall regional pattern of tree radial growth in the middle of the Qilian Mountains in our subsequent analyses.

Tree growth showed consistent variation at the three sites in the northeastern Qaidam Basin (Fig. S3). Mean raw ring-width and BAI values since 1950 were higher than means for the whole period, which suggests unprecedentedly rapid tree growth in the most recent decades. Since 1950, BAI increased significantly at all sites, tree-ring width increased significantly at the DLH and DLH3 (Table 2). We correlated the pairwise coupling of the three tree growth chronologies, and found statistically significant correlations during the common period from 1800 to $2002(r>0.68, p<0.001)$. These combined results suggest that tree growth varied 


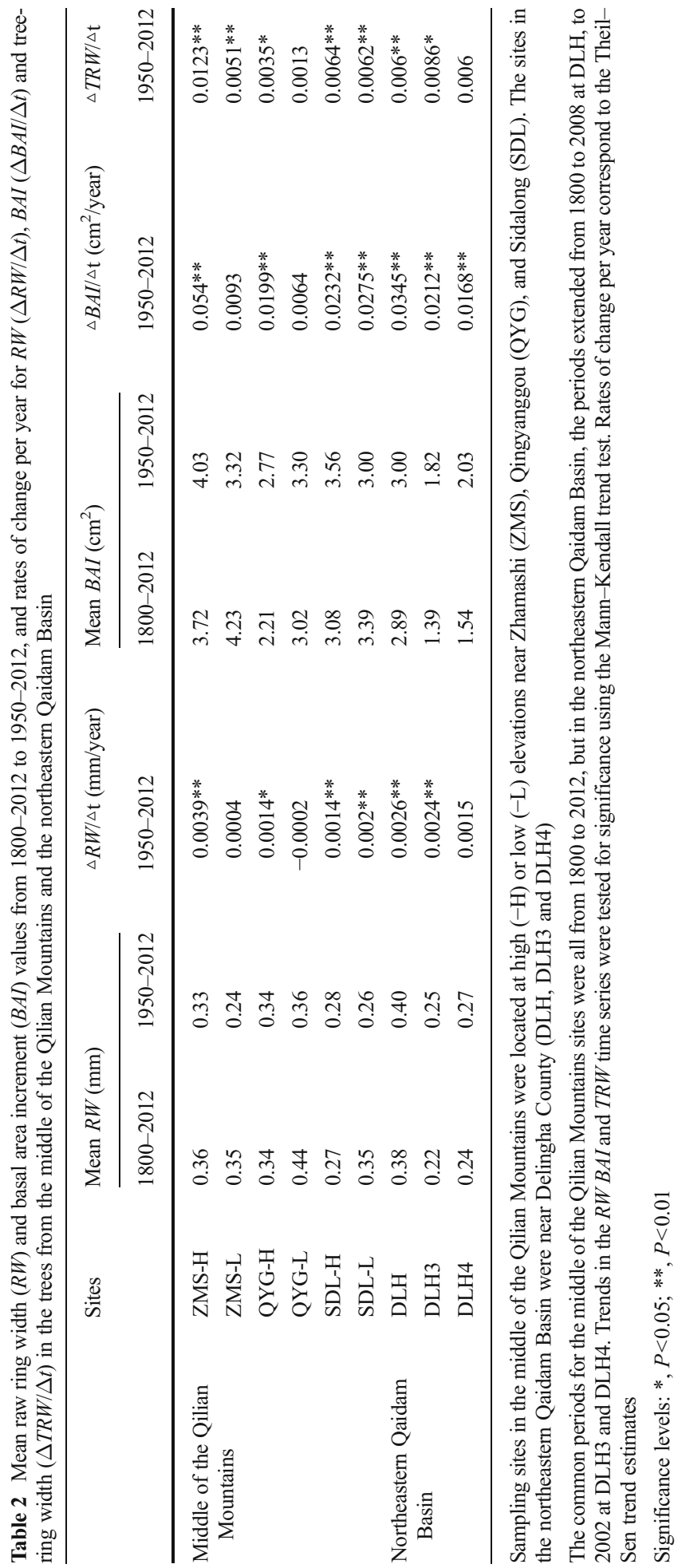


coherently in the northeastern Qaidam Basin, so we averaged the three BAI and tree-ring width chronologies to form the regional composite chronologies in our subsequent analyses.

Comparison of the standardized BAI chronologies and tree-ring width series from the middle of the Qilian Mountains and northeastern Qaidam Basin revealed high synchronicity in the trend of enhanced tree growth since 1950 (Fig. 2b, d, top). Since 1950, the standardized BAI series for both regions increased significantly and similarly (with slopes of 0.029 and $0.028 \mathrm{~cm}^{2}$ year $^{-1}$, respectively), the tree-ring width series also increased significantly. Correlation analysis showed that the tree growth of the two regions were significantly positively correlated ( $r=0.46,0.43$ for the BAI and tree-ring width, respectively, $p<0.01$ ) during the common period from 1800 to 2008. However, the moving-window correlation coefficients decreased after 1950, and were not significantly correlated during most of this period (Fig. 2b, d, bottom). The decreased correlations suggest that tree growth may respond differently to the regional environmental changes, leading to substantially divergent growth responses in the two regions in response to the rapid warming in recent decades.

\subsection{Responses to climate change}

The climatic-response patterns differed between the middle of the Qilian Mountains and northeastern Qaidam Basin in both the response pattern and the signal strength (Table 3 ). In the middle of
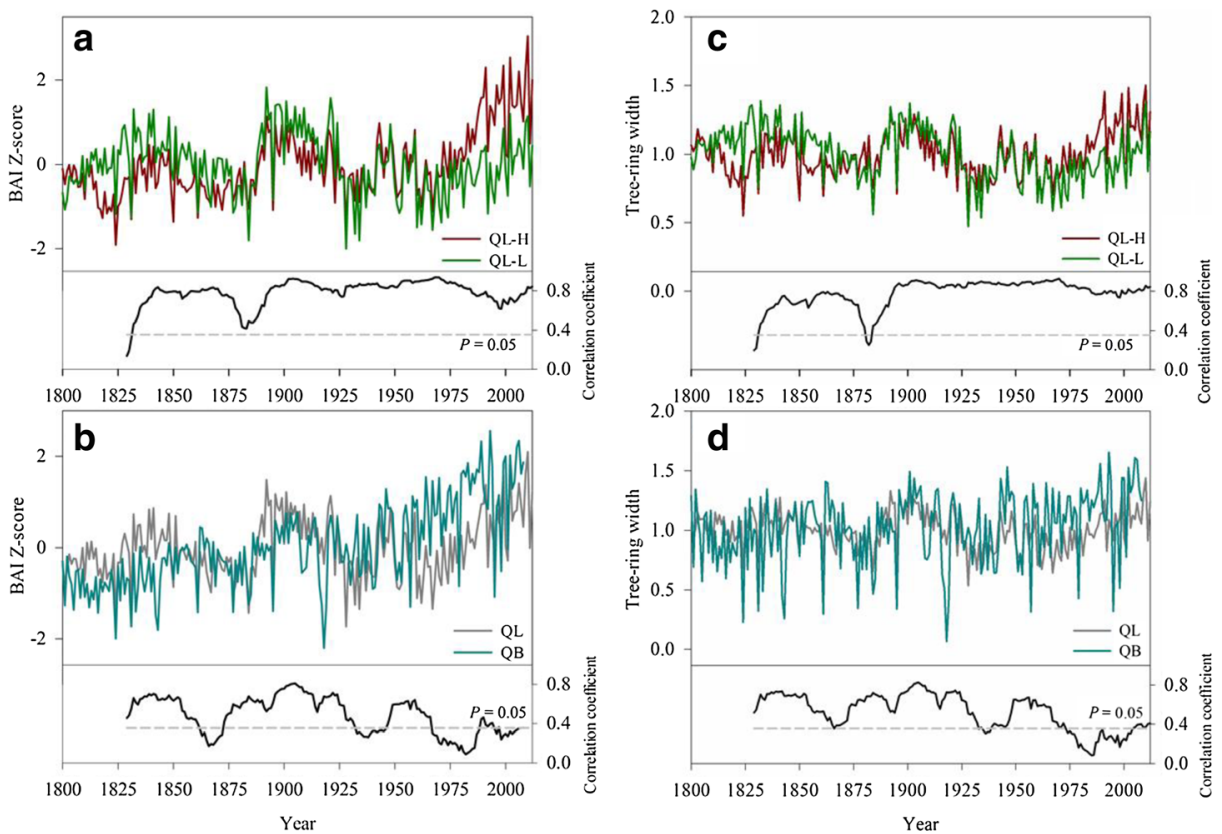

Fig. 2 a Averaged Z-scores for the basal-area increment (BAI) chronologies at the high-elevation (QL-H) and low-elevation (QL-L) sites in the middle of the Qilian Mountains from 1800 to 2012; b Averaged Z-scores for basal-area increment (BAI) chronologies in the middle of the Qilian Mountains (QL) (top) and the northeastern Qaidam Basin (QB) from 1800 to 2012 and from 1800 to 2008, respectively; c Averaged tree-ring width chronologies at the high-elevation (QL-H) and low-elevation (QL-L) sites in the middle of the Qilian Mountains from 1800 to 2012; d Averaged tree-ring width chronologies in the middle of the Qilian Mountains (QL) and the northeastern Qaidam Basin (QB) from 1800 to 2012 and from 1800 to 2008, respectively. The bold black line in each of the bottom panel represents the 30-year moving-window correlation coefficients for the two time series 
Table 3 Correlation coefficients between the regional BAI chronologies and the climate parameters for the highfrequency variations during the periods from 1960 to 2012 in the middle of the Qilian Mountains and from 1957 to 2008 in the northeastern Qaidam Basin

\begin{tabular}{|c|c|c|c|c|c|c|c|c|}
\hline & \multicolumn{4}{|c|}{ Middle of the Qilian Mountains } & \multicolumn{4}{|c|}{ Northeastern Qaidam Basin } \\
\hline & $T_{\text {mean }}$ & $T_{\min }$ & $T_{\max }$ & Precipitation & $T_{\text {mean }}$ & $T_{\min }$ & $T_{\max }$ & Precipitation \\
\hline pAug. & $-0.338^{*}$ & -0.185 & $-0.346^{*}$ & 0.269 & -0.161 & 0.099 & $-0.281^{*}$ & 0.257 \\
\hline pSept. & 0.143 & 0.178 & -0.019 & $0.274^{*}$ & -0.048 & 0.086 & -0.137 & 0.129 \\
\hline pOct. & 0.207 & 0.141 & 0.193 & 0.031 & 0.203 & 0.221 & 0.099 & 0.146 \\
\hline pNov. & 0.188 & $0.282 *$ & 0.045 & 0.075 & 0.041 & 0.084 & 0.012 & $-0.313^{*}$ \\
\hline pDec. & 0.197 & 0.222 & 0.154 & 0.061 & 0.001 & 0.057 & -0.057 & 0.062 \\
\hline Jan. & $0.373 * *$ & $0.434 * *$ & 0.268 & 0.072 & 0.029 & 0.098 & -0.011 & -0.009 \\
\hline Feb. & 0.162 & 0.234 & 0.076 & 0.023 & 0.034 & 0.092 & -0.044 & 0.083 \\
\hline Mar. & $0.278^{*}$ & $0.366^{* *}$ & 0.15 & $0.273^{*}$ & 0.115 & 0.19 & 0.013 & 0.073 \\
\hline Apr. & 0.046 & 0.206 & -0.057 & 0.238 & -0.145 & -0.105 & -0.142 & 0.156 \\
\hline May & -0.246 & 0.002 & -0.252 & $0.287^{*}$ & -0.169 & 0.127 & $-0.287^{*}$ & $0.452 * *$ \\
\hline June & -0.044 & 0.136 & -0.137 & 0.083 & $-0.507 * *$ & 0.003 & $-0.553 * *$ & $0.543^{* *}$ \\
\hline July & -0.007 & 0.162 & -0.093 & 0.212 & 0.031 & 0.159 & -0.046 & -0.049 \\
\hline Aug. & 0.103 & 0.061 & 0.151 & -0.049 & -0.046 & -0.142 & 0.019 & -0.119 \\
\hline Sept. & 0.151 & -0.051 & $0.318^{*}$ & -0.262 & -0.177 & -0.232 & -0.093 & -0.199 \\
\hline Oct. & 0.05 & -0.074 & 0.169 & -0.026 & 0.035 & 0.042 & 0.057 & -0.101 \\
\hline
\end{tabular}

The high-frequency variation was represented by the residuals between the raw data series and the fitted linear regression. The letter " $\mathrm{p}$ " before a month name indicates the previous year. $T_{\operatorname{mean}}, T_{\min }$, and $T_{\max }$ represent the regional monthly mean temperature, mean minimum temperature, and mean maximum temperature variations

Significance levels: *, $P<0.05 ; * *, P<0.01$

the Qilian Mountains, the BAI residuals responded sensitively and positively to $T_{\text {mean }}$ and $T_{\min }$ during the current January and March, and the correlations were stronger for $T_{\min }$ (Table 3). Nevertheless, there were no significant correlations between the northeastern Qaidam Basin BAI series and the climatic parameters during the growing season, except for a weak significant correlation $(r=0.29, p<0.05)$ with precipitation in May. In the northeastern Qaidam Basin, the BAI series was significantly $(p<0.01)$ positively correlated with precipitation in May and June and significantly negatively correlated with $T_{\max }$ during this period and with $T_{\text {mean }}$ in June. No significant correlation was found between the BAI residuals and $T_{\min }$ in the northeastern Qaidam Basin (Table 3). The climatic-response patterns of tree-ring width residuals showed similar patterns and signal strengths to the BAI residuals in the two regions (Table S3) These results suggest that winter mean and minimum temperatures influenced tree growth in the middle of the Qilian Mountains, whereas growth in the northeastern Qaidam Basin was mostly affected by precipitation and temperature variations during the early growing season (May and June).

To reveal the temporal changes in tree growth and their relationships with climatic variations, we conducted a 21-year moving-window correlation analysis for the two regional high-frequency BAI, tree-ring width series and their corresponding most important climate parameters (based on the correlations in Table 3) for the periods from 1960 to 2012 (middle of the Qilian Mountains) and from 1957 to 2008 (northeastern Qaidam Basin) (Fig. 3). In the middle of the Qilian Mountains, $T_{\min } T_{\max }$ and $T_{\text {mean }}$ in the previous winter showed increasingly significant positive correlations with BAI and tree-ring width chronologies over time (Fig. 3a, c). In the northeastern Qaidam Basin, 


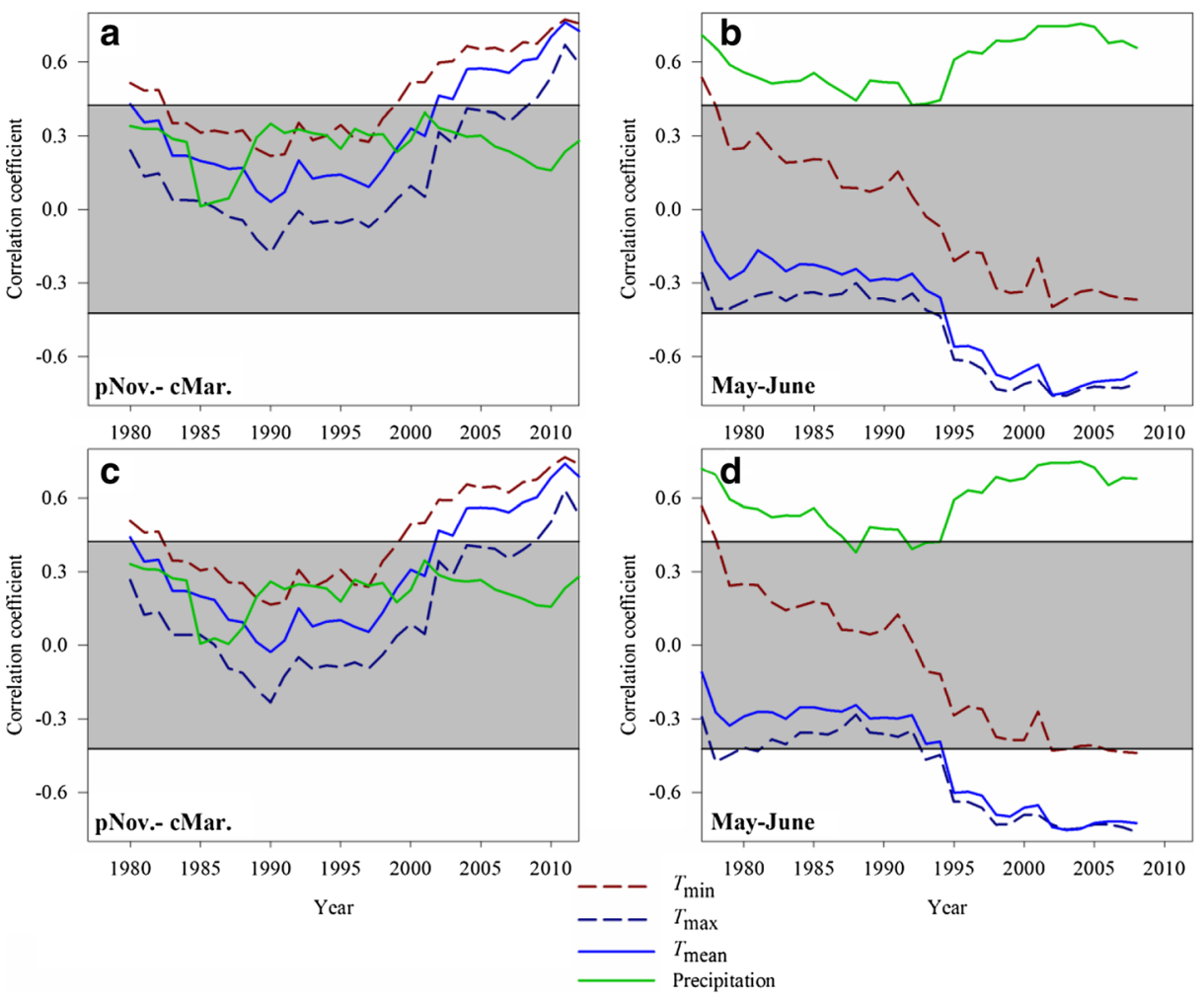

Fig. 3 The 21-year window moving correlations of high-frequency basal-area increment (BAI), tree-ring width chronologies and climate variables from the previous November to the current March in the middle of the Qilian Mountains during 1960 to 2012 (a, c) and the current May to June in the northeastern Qaidam Basin during 1957 to $2008(\mathbf{b}, \mathbf{d})$. The values outside of the shaded areas represent the significance at $95 \%$ confidence level. The climate variables were the monthly minimum temperature $\left(T_{\min }\right)$, monthly maximum temperature $\left(T_{\max }\right)$, monthly mean temperature $\left(T_{\text {mean }}\right)$ and monthly total precipitation

precipitation during the early growing season was consistently significantly and positively correlated with the BAI, tree-ring width series from the whole period 1957 to 2008 (Fig. 3b, d). The strong negative correlations trends between BAI, tree-ring width and both $T_{\text {mean }}$ and $T_{\max }$ from May to June after the interval of 1975 to 1995 indicated that increasing temperature has significantly suppressed tree growth in recent years. The correlation between BAI, tree-ring width and $T_{\min }$ in May and June changed dramatically, from a significant positive correlation to a nonsignificant negative correlation (Fig. 3b, d). These results indicated that the warming climate gradually enhanced tree growth in the middle of the Qilian Mountains, but decreased tree growth in the northeastern Qaidam Basin.

\section{Discussion}

\subsection{Consistent tree growth at high and low elevations}

Salzer et al. (2009) reported that tree radial growth after 1950 at three upper-treeline sites in western North America was unprecedentedly rapid, and the growth surge was occurred only in 
a limited elevational band within $\sim 150$ m of upper treeline, regardless of treeline elevation. In contrast, the present study found consistent patterns of Qilian juniper growth at the high- and low-elevation sites. Consistent growth at high- and low-elevation sites has been reported in other parts of the Qinghai-Tibetan Plateau (Gao et al. 2013; Yang et al. 2013). Water stress was the main climatic factor that caused homogeneous tree growth across an altitudinal gradient in the western of the Qilian Mountains (Yang et al. 2013). However, in western North America, tree growth at the upper treeline increased significantly with increasing temperature, but growth chronologies of the non-treeline were positively correlated with precipitation (Salzer et al. 2009). Though we found that the previous winter's temperature most strongly controlled the growth of Qilian juniper at the Qilian Mountains sites, there were no striking differences among the altitudes. Thus, we averaged the high- and low-elevation chronologies and used the result to represent the regional tree growth.

\subsection{Divergent response to the warming of different regions}

Our results revealed consistently increasing tree radial growth in the middle of the Qilian Mountains and northeastern Qaidam Basin since 1950. Recently, speedup of tree growth in the Tianshan Mountains, where the climate conditions were similar to our present study, has been evidenced in both the high- and low-elevations (Qi et al. 2015). However, other studies found large-scale tree growth decline in the Hemi-Boreal forests (Wu et al. 2012, 2013, 2014b; Liu et al. 2013). The growth decline were mainly caused by the warming-induced water limitations, especially the warmer spring (Wu et al. 2012, 2013); while, previous autumn and winter temperature improved the speedup of tree growth in the Tianshan Mountains (Qi et al. 2015).

Previous researches using dendroclimatological methods have demonstrated that temperatures during the previous winter played a dominant role in growth of Qilian juniper in the middle of the Qilian Mountains (Liu et al. 2005; Gao et al. 2013). In addition, precipitation during the previous winter (mostly in the form of snow) also contributed to the recent enhancement of tree growth (Fig. 3a, c). In the northeastern Qaidam Basin, temperatures during the early growing season $\left(T_{\text {mean }}, T_{\min }\right.$, and $\left.T_{\max }\right)$ played an increasingly critical role in determining tree growth. Regional $T_{\text {mean }}$ and $T_{\max }$ have been increasing significantly in recent decades (Table 1, Fig. S2), which resulted in increasing evapotranspiration and drought stress. In addition, increasing $T_{\min }$ prior to the interval of 1959 to 1979 significantly increased tree growth, but the strength of the correlation decreased dramatically and eventually decreased tree growth afterwards the interval of 1973 to 1993 (Fig. 3b, d).

The different temperature responses of trees in the two regions may be related to their different moisture conditions (Porter and Pisaric 2011; Lévesque et al. 2013). Water limitations and warming-induced drought are primary drivers of a regional tree growth decline or even increased tree mortality in recent decades (e.g., Allen et al. 2010; Anderegg et al. 2013; Liu et al. 2013; Williams et al. 2013). In the northeastern Qaidam Basin, Qilian juniper is sparsely distributed, and is mostly found in mountainous areas where above-average precipitation results from orographic effects ( $\mathrm{Du}$ and Sun 1990). When temperatures during the early growing season increase, evapotranspiration increases, and the increasingly severe water limitations would threaten tree growth; conversely, decreasing temperatures would decrease evapotranspiration and be helpful for tree growth. Thus, tree growth in this arid region mostly depended on the available water (Shao et al. 2005; Yang et al. 2014). However, in the middle of the Qilian Mountains, water limitations would be less severe, and a warmer winter would protect the roots of trees from frost damage and advance the onset of xylem formation and 
primary growth (Liu et al. 2005; Gao et al. 2013; Huang et al. 2014). In addition, monitoring intra-annual variability in radial growth also found that the previous growing season temperature was a major limiting factor in Qilian juniper growth in the middle of the Qilian Mountains (Wang et al. 2015) Thus, temperatures would potentially be more critical to juniper growth in the Qilian Mountains. Nevertheless, temperature and precipitation have interacting effects during the growing season, and their interaction would also affect tree growth in the middle of the Qilian Mountains. Furthermore, the relationships between the regional standardized BAI series and the corresponding Palmer Drought Severity Index (PDSI), standardized precipitation-evapotranspiration index (SPEI) during the growing season from 1955 to 2008, and also the growing season precipitation from 1960 to 2008 confirmed the divergent effects of drought on tree growth in our two study areas (Fig. S4). Thus, it is likely that the increased growth of Qilian juniper in the northeastern Qaidam Basin was mainly caused by the significant increase in precipitation, whereas the growth increase in the middle of the Qilian Mountains was dominated by increasing temperatures.

Future temperatures and precipitation in the Qinghai-Tibetan Plateau have been simulated using many climate models (e.g. Su et al. 2013; Chen and Frauenfeld 2014). All of the simulation results predict a warming trend in the 21 st century, with the amplitude of the warming larger than that of the increase in precipitation for the Qinghai-Tibetan Plateau ( $\mathrm{Su}$ et al. 2013; Chen and Frauenfeld 2014). If the temperature continues to rise faster than the precipitation increases, then growth of Qilian juniper in the middle of the Qilian Mountains should increase steadily, whereas growth in the northeastern Qaidam Basin may remain stable or even decrease.

The observed tree growth trends could also be partly caused by increasing atmospheric $\mathrm{CO}_{2}$ and nitrogen deposition (Huang et al. 2007; Law 2013). Empirical evidence from experiments with a controlled $\mathrm{CO}_{2}$ concentration and from free-air $\mathrm{CO}_{2}$ enrichment (FACE) experiments suggest the existence of a " $\mathrm{CO}_{2}$ fertilization" effect caused by the rising $\mathrm{CO}_{2}$ concentration (Ainsworth and Long 2005; Huang et al. 2007), and the increased intrinsic water use efficiency (iWUE) that results from increasing atmospheric $\mathrm{CO}_{2}$ concentrations could also stimulate tree growth (Ainsworth and Rogers 2007; Niu et al. 2011). However, several studies have indicated that trees did not significantly increase their growth and may even have experienced a growth decline despite increasing atmospheric $\mathrm{CO}_{2}$ concentrations and increasing iWUE in natural forest ecosystems (Peñuelas et al. 2011; Wang et al. 2012; Lévesque et al. 2014). In addition, a persistent increase in nitrogen deposition caused by human activity has been proposed to explain the increased carbon sequestration by forest ecosystems (Schlesinger 2009; Leonardi et al. 2012; Law 2013). Whereas, recent evidence suggests that such nitrogen deposition may have little effect on the boreal forest carbon cycle (Gundale et al. 2014) and further works are need to clarify this perplexity. Thus, the roles and the magnitudes of the impacts of rising $\mathrm{CO}_{2}$ concentrations and nitrogen deposition on tree growth remains unclear, and in situ observations in the northeastern Qinghai-Tibetan Plateau will be required in the future.

\section{Conclusions}

In summary, our results indicated that consistent patterns of tree growth have occurred at high and low elevations in the middle of the Qilian Mountains, and that tree growth in the different regions of the northeastern Qinghai-Tibetan Plateau showed highly consistent trends (increased growth since 1950), but with different driving factors. The details of the response 
and a moving-window correlation analysis for the relationship of BAI and tree-ring width series and regional climate factors demonstrated that increasing temperatures (particularly in the winter) accelerated tree growth in the middle of the Qilian Mountains, but decreased tree growth in the northeastern Qaidam Basin. Conversely, increasing precipitation during the growing season stimulated growth in the Qaidam Basin. These results suggest that growth of Qilian juniper in the middle of the Qilian Mountains should increase steadily in the future, whereas growth may remain stable or even decrease in the northeastern Qaidam Basin. Our findings increase our understanding of the factors that drive tree growth (here, temperature and precipitation) under certain environmental conditions. The divergent responses of the trees in our two study regions to temperature and precipitation should therefore be incorporated into predictions of future forest carbon cycling.

Acknowledgments This research was supported by the National Natural Science Foundation of China (41171167), by the Major State Basic Research Development Program of China (973 Program) (2013CBA01808), and by the self-determination project of the State Key Laboratory of Cryospheric Sciences (SKLCS-ZZ-2015-01-12). We gratefully acknowledge the journal's anonymous reviewers for their constructive comments on earlier versions of this manuscript.

\section{References}

Ainsworth EA, Long SP (2005) What have we learned from 15 years of free-air $\mathrm{CO}_{2}$ enrichment (FACE)? A meta-analytic review of the responses of photosynthesis, canopy properties and plant production to rising $\mathrm{CO}_{2}$. New Phytol 165:351-372

Ainsworth EA, Rogers A (2007) The response of photosynthesis and stomatal conductance to rising $\left[\mathrm{CO}_{2}\right]$ : mechanisms and environmental interactions. Plant Cell Environ 30:258-270

Allen CD, Macalady AK, Chenchouni $\mathrm{H}$ et al (2010) A global overview of drought and heat-induced tree mortality reveals emerging climate change risks for forests. For Ecol Manag 259:660-684

Anderegg WRL, Kane JM, Anderegg LDL (2013) Consequences of widespread tree mortality triggered by drought and temperature stress. Nat Clim Chang 3:30-36

Chen L, Frauenfeld OW (2014) Surface air temperature changes over the twentieth and twenty-first centuries in China simulated by 20 CMIP5 models. J Clim 27:3920-3937

Chen H, Zhu Q, Peng C et al (2013) The impacts of climate change and human activities on biogeochemical cycles on the Qinghai-Tibetan Plateau. Glob Chang Biol 19:2940-2955

Cook ER (1985) A time series analysis approach to tree-ring standardization. PhD dissertation. University of Arizona, Tucson, AZ, USA

Du Q, Sun SZ (1990) Vegetation in the Qaidam Basin Region and its utilization (in Chinese). Science Press, Beijing

Fang J, Kato T, Guo Z et al (2014) Evidence for environmentally enhanced forest growth. PNAS 111:9527-9532

Gao L, Gou X, Deng Y, Liu W, Yang M, Zhao Z (2013) Climate-growth analysis of Qilian juniper across an altitudinal gradient in the central Qilian Mountains, northwest China. Trees 27:379-388

Gundale MJ, From F, Bach LH, Nordin A (2014) Anthropogenic nitrogen deposition in boreal forests has a minor impact on the global carbon cycle. Glob Chang Biol 20:276-286

Holmes RL (1983) Computer-assisted quality control in tree-ring dating and measurement. Tree Ring Bull 43: $69-78$

Huang J-G, Bergeron Y, Denneler B, Berninger F, Tardif J (2007) Response of forest trees to increased atmospheric $\mathrm{CO}_{2}$. Crit Rev Plant Sci 26:265-283

Huang J, Guan X, Ji F (2012) Enhanced cold-season warming in semi-arid regions. Atmos Chem Phys 12:53915398

Huang J-G, Deslauriers A, Rossi S (2014) Xylem formation can be modeled statistically as a function of primary growth and cambium activity. New Phytol 203:831-841

Law B (2013) Biogeochemistry: nitrogen deposition and forest carbon. Nature 496:307-308

Leonardi S, Gentilesca T, Guerrieri R et al (2012) Assessing the effects of nitrogen deposition and climate on carbon isotope discrimination and intrinsic water-use efficiency of angiosperm and conifer trees under rising $\mathrm{CO}_{2}$ conditions. Glob Chang Biol 18:2925-2944 
Lévesque M, Saurer M, Siegwolf R, Eilmann B, Brang P, Bugmann H, Rigling A (2013) Drought response of five conifer species under contrasting water availability suggests high vulnerability of Norway spruce and European larch. Glob Chang Biol 19:3184-3199

Lévesque M, Siegwolf R, Saurer M, Eilmann B, Rigling A (2014) Increased water-use efficiency does not lead to enhanced tree growth under xeric and mesic conditions. New Phytol 203:94-109

Liu X, Qin D, Shao X, Chen T, Ren J (2005) Temperature variations recovered from tree-rings in the middle Qilian Mountain over the last millennium. Sci China Ser D 48:521-529

Liu H, Park Williams A, Allen CD et al (2013) Rapid warming accelerates tree growth decline in semi-arid forests of Inner Asia. Glob Chang Biol 19:2500-2510

Niu S, Xing X, Zhang Z et al (2011) Water-use efficiency in response to climate change: from leaf to ecosystem in a temperate steppe. Glob Chang Biol 17:1073-1082

Peñuelas J, Canadell JG, Ogaya R (2011) Increased water-use efficiency during the 20th century did not translate into enhanced tree growth. Glob Ecol Biogeogr 20:597-608

Peters RL, Groenendijk P, Vlam M, Zuidema PA (2015) Detecting long-term growth trends using tree rings: a critical evaluation of methods. Glob Chang Biol 21:2040-2054

Phipps RL, Whiton JC (1988) Decline in long-term growth trends of white oak. Can J For Res 18:24-32

Porter TJ, Pisaric MFJ (2011) Temperature-growth divergence in white spruce forests of Old Crow Flats, Yukon Territory, and adjacent regions of northwestern North America. Glob Chang Biol 17:3418-3430

Poulter B, Frank D, Ciais P et al (2014) Contribution of semi-arid ecosystems to interannual variability of the global carbon cycle. Nature 509:600-603

Qi Z, Liu H, Wu X, Hao Q (2015) Climate-driven speedup of alpine treeline forest growth in the Tianshan Mountains, Northwestern China. Glob Chang Biol 21:816-826

Salzer MW, Hughes MK, Bunn AG, Kipfmueller KF (2009) Recent unprecedented tree-ring growth in bristlecone pine at the highest elevations and possible causes. PNAS 106:20348-20353

Schlesinger WH (2009) On the fate of anthropogenic nitrogen. PNAS 106:203-208

Shao X, Huang L, Liu H, Liang E, Fang X, Wang L (2005) Reconstruction of precipitation variation from tree rings in recent 1000 years in Delingha, Qinghai. Sci China Ser D 48:939-949

Shao X, Wang S, Zhu H et al (2009) A 3585-year ring-width dating chronology of Qilan juniper from the northeastern Qinghai-Tibetan Plateau. IAWA J 30:379-394

Shao X, Xu Y, Yin Z, Liang E, Zhu H, Wang S (2010) Climatic implications of a 3585-year tree-ring width chronology from the northeastern Qinghai-Tibetan Plateau. Quat Sci Rev 29:2111-2122

Su F, Duan X, Chen D, Hao Z, Cuo L (2013) Evaluation of the global climate models in the CMIP5 over the Tibetan Plateau. J Clim 26:3187-3208

Wang W, Liu X, An W, Xu G, Zeng X (2012) Increased intrinsic water-use efficiency during a period with persistent decreased tree radial growth in northwestern China: causes and implications. For Ecol Manag 275: $14-22$

Wang Z, Yang B, Deslauriers A, Bräuning A (2015) Intra-annual stem radial increment response of Qilian juniper to temperature and precipitation along an altitudinal gradient in northwestern China. Trees 29:25-34

Williams AP, Allen CD, Millar CI, Swetnam TW, Michaelsen J, Still CJ, Leavitt SW (2010) Forest responses to increasing aridity and warmth in the southwestern United States. PNAS 107:21289-21294

Williams AP, Allen CD, Macalady AK et al (2013) Temperature as a potent driver of regional forest drought stress and tree mortality. Nat Clim Chang 3:292-297

Wu X, Liu H, Guo D, Anenkhonov OA, Badmaeva NK, Sandanov DV (2012) Growth decline linked to warming-induced water limitation in hemi-boreal forests. PLoS ONE 7:e42619

Wu X, Liu H, Wang Y, Deng M (2013) Prolonged limitation of tree growth due to warmer spring in semi-arid mountain forests of Tianshan, northwest China. Environ Res Lett 8:024016

Wu C, Hember RA, Chen J et al (2014) Accelerating forest growth enhancement due to climate and atmospheric changes in British Colombia, Canada over 1956-2001. Sci Rep 4. doi:10.1038/srep04461

Wu X, Liu H, He L et al (2014b) Stand-total tree-ring measurements and forest inventory documented climateinduced forest dynamics in the semi-arid Altai Mountains. Ecol Indic 36:231-241

Yang B, He M, Melvin TM, Zhao Y, Briffa KR (2013) Climate control on tree growth at the upper and lower treelines: a case study in the Qilian Mountains, Tibetan Plateau. PLoS ONE 8:e69065. doi:10.1371/journal. pone.0069065

Yang B, Qin C, Wang J, He M, Melvin TM, Osborn TJ, Briffa KR (2014) A 3,500-year tree-ring record of annual precipitation on the northeastern Tibetan Plateau. PNAS 111:2903-2908

Yu G, Chen Z, Piao S et al (2014) High carbon dioxide uptake by subtropical forest ecosystems in the East Asian monsoon region. PNAS 111:4910-4915 